\title{
Sustainable management of artisanal fisheries in developing countries; the need for expert systems: the case of the Pêchakour Expert System (PES)
}

\author{
S.-C. Chakour \\ Jijel University, Algeria
}

\begin{abstract}
Environmental problems are very often ascribed to pollution. Nevertheless, various other environmental impacts are also associated with abusive exploitation of natural resources that remain abundant in many developing countries. An urgent public intervention Boncoeur [1], therefore, seems necessary and reasonable public policies must be found. Since economic resources and coastal environment in some countries, notably in developing ones, lack expertise, the recourse to the Expert System triggers public attention and intervention for sustainable management of resources. In this respect, the present article examines advantages of expert systems, notably the Pêchakour Expert System (PES), as being helpful tools in decision-making. Another objective of this article is to highlight the efficiency and practical character of such expert systems.
\end{abstract}

Keywords: marine resources, artisanal fisheries, sustainable management, public policies, decision, Pêchakour Expert System.

\section{Introduction}

The development of the fishing sector in Algeria calls for an appropriate adjustment of fisheries in the context of sustainable management of resources and fisheries activities Chakour and Allegret [2]. This must rely on good governance based on indicators and relevant information, so as to orientate the public intervention. As a precaution, it is also necessary to use simulations that can put in evidence the after-effects of all economic or technical activities. 
Considering the difficulties facing managers of the fishing sector, either on the methodological plan or the conceptual one Le Gallic [3], the use of expert systems can undoubtedly contribute to resolving the problematic issue of the sustainable management of the sector in question, notably in developing countries. In this end, the present article studies the advantages of expert systems, notably the Pêchakour Expert System (PES) as being helpful tools in decision- making. Another objective of this article is to underline the efficiency and practical character of such expert systems.

\section{Presentation of the PES}

It is necessary to recall that the expert system is, conceptually, founded on the bioeconomical model "Pêchakour" Chakour and Boncoeur [4] which is theoretically justified on the basis of economic resources.

\subsection{Organization and functioning of the PES}

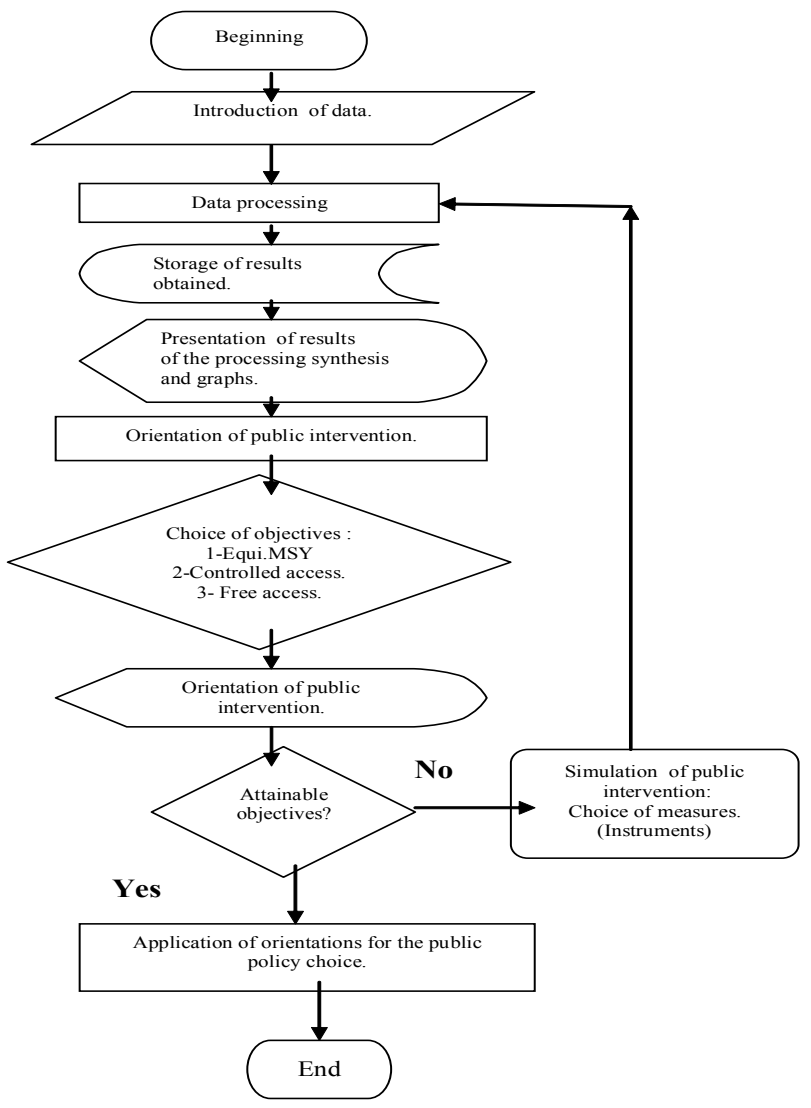

Figure 1: $\quad$ Summary of the functioning of the PES. 


\section{Contribution of the PES to the management of artisanal fisheries in Algeria}

Methodologically, the PES is about replicating the real conditions of fishing activities, in a fishery reserved to the "small professions" in the gulf of Ziama. While leaning on results of an empirical approach that has permitted the identification of some technical and bioeconomical indicators, the PES Chakour [5] will be used for the management of the fishery in question.

Table 1: $\quad$ Necessary data introduced.

\begin{tabular}{|c|c|c|c|c|}
\hline $\begin{array}{c}\text { Type of } \\
\text { information }\end{array}$ & Data & Definition & Value & Unit. \\
\hline \multirow[t]{2}{*}{ Biological } & $a$ & $\begin{array}{l}\text { Biological parameter of the } \\
\text { captures function. }\end{array}$ & 0.0002 & Coefficient \\
\hline & $b$ & $\begin{array}{l}\text { Biological parameter of the } \\
\text { captures function. }\end{array}$ & 1103 & Coefficient \\
\hline \multirow{7}{*}{ Economical } & Im & $\begin{array}{l}\text { Middle value of acquisition of a } \\
\text { fishing unit. }\end{array}$ & 3000 & Thousands of dinars \\
\hline & Taxes & $\begin{array}{l}\text { It is the total value of taxes on } \\
\text { the whole of the flotilla and the } \\
\text { marine strength by period of } \\
\text { analysis (month). }\end{array}$ & 09 & $\begin{array}{l}\text { Thousands of dinars } \\
\text { by period (month) }\end{array}$ \\
\hline & Insurance & $\begin{array}{l}\text { It is the total value of } \\
\text { insurances on the whole of the } \\
\text { flotilla and the marine strength } \\
\text { by period of analysis (month). }\end{array}$ & 05 & $\begin{array}{l}\text { Thousands of dinars } \\
\text { by period (month) }\end{array}$ \\
\hline & Role & $\begin{array}{l}\text { It is the total value of roles for } \\
\text { the whole of the flotilla and the } \\
\text { marine strength by period of } \\
\text { analysis (month). }\end{array}$ & 08 & $\begin{array}{l}\text { Thousands of dinars } \\
\text { by period (month) }\end{array}$ \\
\hline & pe: & Cost by unit of effort. & 03 & $\begin{array}{l}\text { Thousands of dinars } \\
\text { by unit of effort (exit) }\end{array}$ \\
\hline & $p c:$ & Price of sale of a captured unit. & 300 & $\begin{array}{l}\text { Thousands of dinars } \\
\text { by ton }\end{array}$ \\
\hline & a: & $\begin{array}{lll}\text { Expresses the part of } & \text { of } \\
\text { endowments independently } & \text { to } \\
\text { amortizations of the effort. } & \\
\end{array}$ & 0.001 & $\begin{array}{l}\text { Rate between } 0 \text { and } 1 \\
:[0,1] \text {. }\end{array}$ \\
\hline \multirow{4}{*}{ Technical } & $N$ & $\begin{array}{l}\text { Size of the registered flotilla } \\
\text { exercising in the fishery. }\end{array}$ & 40 & $\begin{array}{l}\text { Number of fishing } \\
\text { unit. }\end{array}$ \\
\hline & $t$ & $\begin{array}{l}\text { The length of life, in year, of a } \\
\text { fishing unit (Boat) }\end{array}$ & 20 & Years. \\
\hline & $S$ & $\begin{array}{l}\text { The average number of Units of } \\
\text { effort (output) by unit of fishing } \\
\text { (vessel) and per year. }{ }^{1}\end{array}$ & 150 & Exits per year. \\
\hline & $\begin{array}{l}\text { Period of } \\
\text { analysis. }\end{array}$ & $\begin{array}{l}\text { The period of analysis is } \\
\text { tributary of the period of } \\
\text { observation in the case of } \\
\text { empirical approaches. }\end{array}$ & month & The month. \\
\hline
\end{tabular}

${ }^{1} \boldsymbol{S}$ and $\boldsymbol{t}$ serve to calculate $\boldsymbol{n}$ : length of life in equivalent effort. It is about the number of effort units, necessary to amortize a unit of fishing (vessel). With: $\boldsymbol{n}=\boldsymbol{S}$. $\boldsymbol{t}$. 


\subsection{Source of data}

The data below has been gathered from the empirical approach Chakour [6] where an investigation and the follow-up fishing activities are exercised by the flotilla "small profession" (the term "Small profession" for the artisanal fishing activity exercised by the small crafts or the small vessels will be use throughout this presentation. It is the integral translation of "Petits métiers" in French) in the gulf of Ziama.

The introduction of technical, biological and economical data is the most important phase. The data will be will validated and processed . The storage of information will be displayed on the user's demand.

\subsection{Results of PES Processing}

\subsubsection{The synthesis}

The PES allows for the displaying of three types of curves, including a curve of synthesis. These allow, in turn, the presentation of three functions: the total income function (RT), the total costs function (CT) and the total profits function (Pi). Information on the different balances is tabulated. The following two figures summarize the results of the processing.

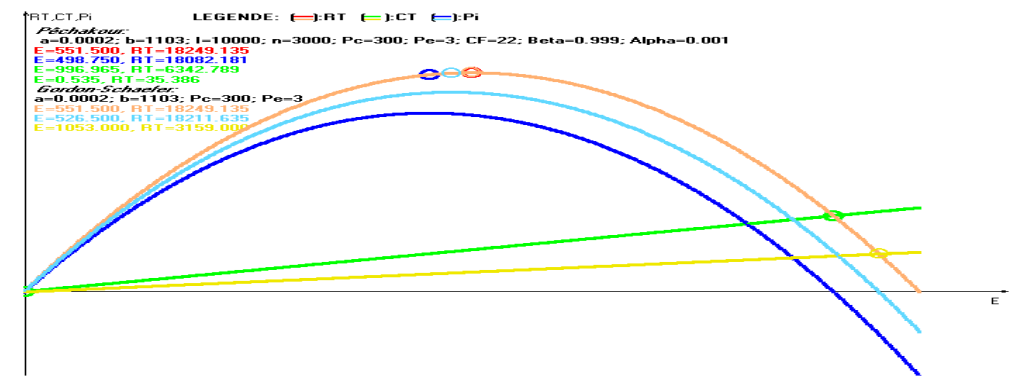

Figure 2: Representing curves.

The diagram and the summary table above are important references for managers in that they not only inform us on the different balances, while proposing a comparison between the Gordon-Schaefer model Gordon [7] and Schaefer [8] and the Pêchakour model, but also show levels of incomes and profits corresponding to the different balances. However, this information is not enough in itself, and a second processing consolidated by susceptible interpretations to orientate public intervention is necessary. Such a task is now possible because of the so-called PES.

\subsubsection{Contribution of the PES to the orientation of public intervention}

The orientations presented below come from the processing of information.

In terms of public intervention, the PES offers the choice between: 
a. Action on the limitation of the fishing effort by endowing the limits not to exceed, the latter will serve for the delimitation of the size of the flotilla "small professions" being exercised in the Gulf of Ziama,

b. Action on the system of quotas by giving the levels of desirable captures "admitted" that are related to every balance and the quotas by the corresponding fishing unit.

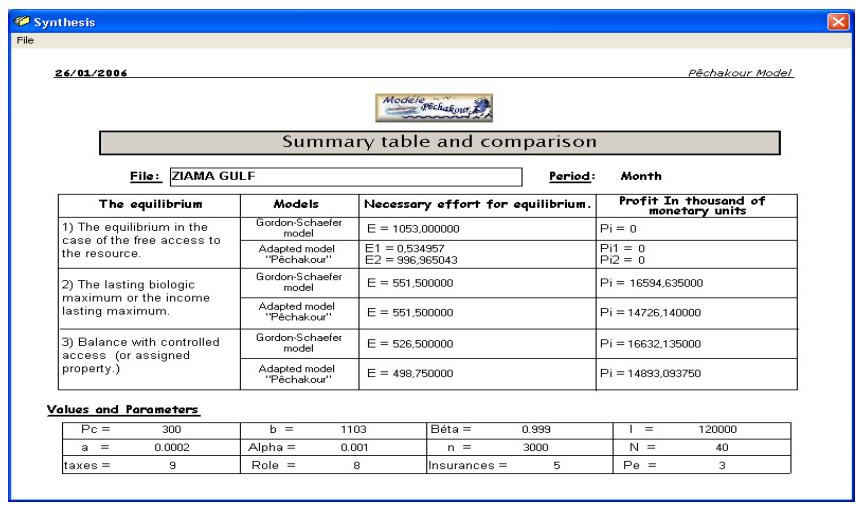

Figure 3: $\quad$ Summary of results.

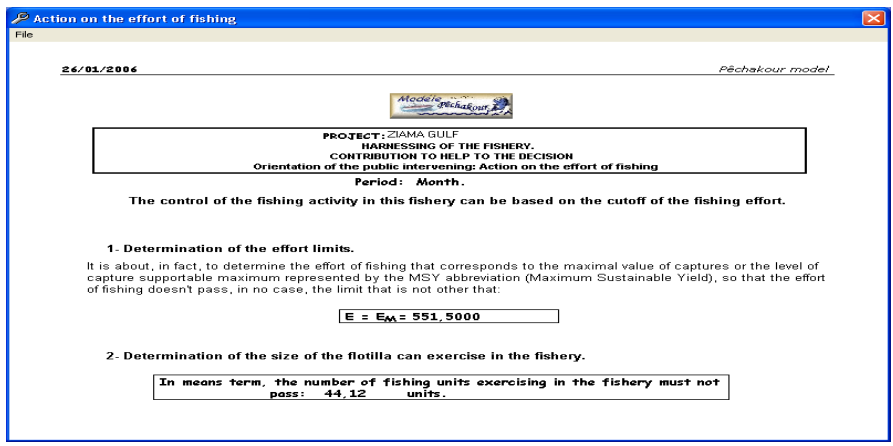

Figure 4: Orientations proposed by the PES: action on the effort of fishing.

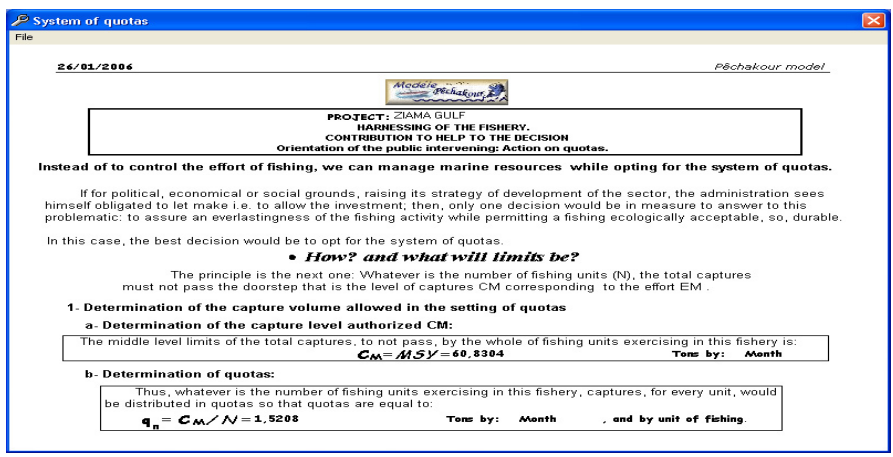

Figure 5: Orientations proposed by the PES: system of quotas. 


\subsubsection{Orientations within the sustainable biological maximum}

- Within the balance linked to the sustainable biological maximum Clark [9], the rhythm of exploitation must be respected by avoiding to bypass "the limit effort" which must not exceed $\mathrm{E}=551.5$ units of effort per fishing unit and month. In fact, managers can delimitate the size of the flotilla which must not bypass, in this case, a total of 44.12 fishing units. Therefore, the main orientation is based on limiting the fishing effort. This can be done by determining, first, the effort limits that must not be exceeded and, second, by determining the ideal size of the flotilla in order not to exceed the MSY. The information also helps to make investment policies, for example, in our case, the size of the flotilla i.e. small professions that must not exceed 44.12 units (44 units). Decision-makers should take the amount of this limit into consideration knowing that by rejecting all projects of "small profession" investment in the site in question if limits were not be respected.

- If the action on the effort proves difficult, one can focus his decision on the system of quotas. This is done by recommending a delimitation of the monthly level of captures by a limit running to $\mathrm{CM}=60.8305$ tons, distributed in quotas of 1.5208 tons per fishing unit and month.

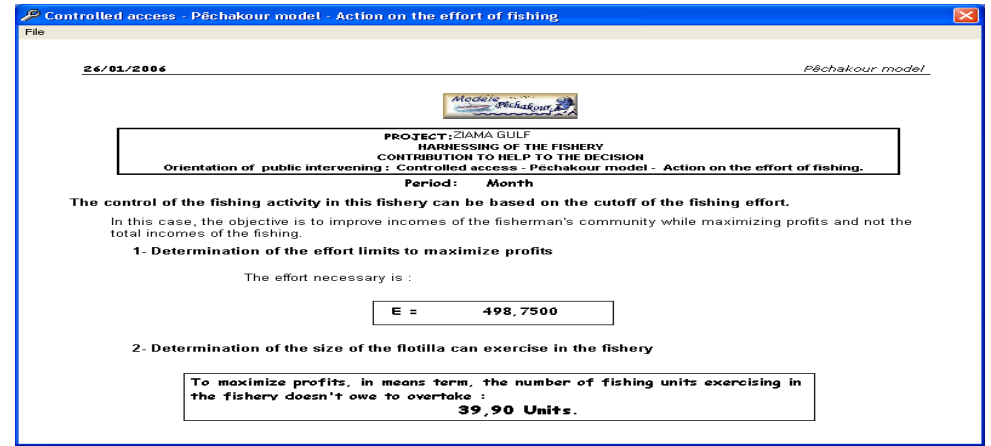

Figure 6: Orientations proposed by the PES: action on the effort of fishing.

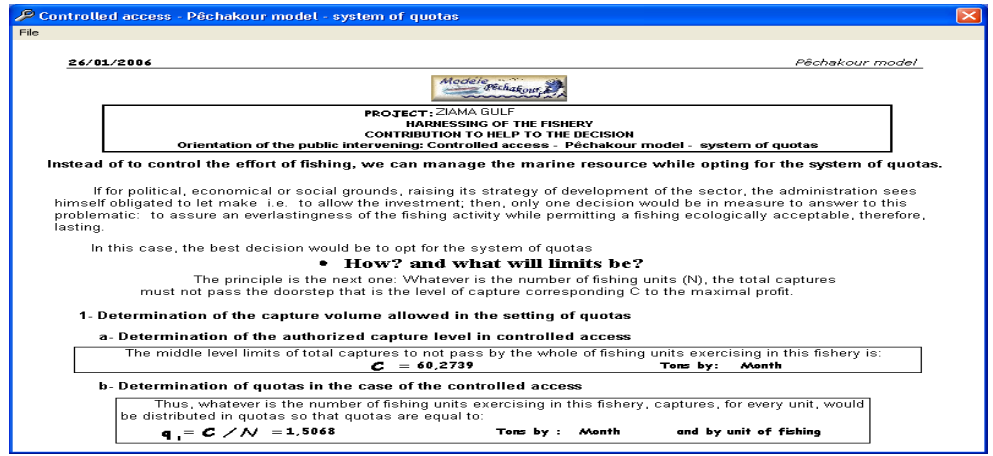

Figure 7: Orientations proposed by the expert system: system of quotas. 


\subsubsection{Orientations in case of controlled access to the resource}

Orientations, within the controlled access, come from the hypothesis of profit maximization Gordon [10] while endowing the decision-makers of pertinent information on the profitability of the fishery. Indeed, the target would be the profits function. In the case studied, the necessary effort to maximize profits of the present fishery is 498.75 units of effort per month. Considering the equivalent of the effort exercised by a flotilla of a size of 39.90 fishing units i.e. "Small profession" excess of this limit, would lead to a reduction of profits. One can also resort to the system of quotas in order to maintain profits at a maximal level Mesnil [11]. To do so, he has to maintain the level of captures at about 60.279 tons per month. This can be achieved by opting for quotas running to 1.5068 tons per fishing unit per month.

\subsection{Findings analysis}

With reference to the obtained results, the $\boldsymbol{P E S}$ shows a remarkable ability in treating and presenting both applicable and reliable information, as compared to those from the manual processing. In addition to this, the strength and the "advisor" character of the $\boldsymbol{P E S}$ go beyond the mere presentation of information as it helps decision-makers taking appropriate and reasonable actions. Subsequently, this achievement is due to PES guidelines emanating from various situations and objectives.

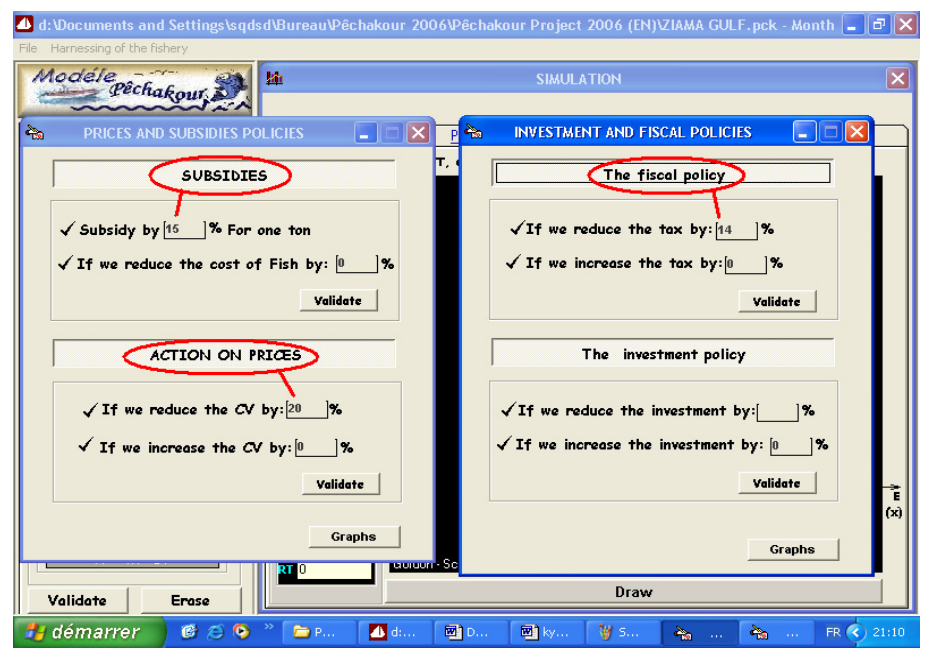

Figure 8: Action on the fiscal and prices policies.

\subsection{Simulation of public intervention with the intention of developing policies}

In addition to the purpose of public policies, the simulation of public intervention permits the consideration of scenarios through fixing objectives and evaluating 
impacts. In what follows, attention should be focused on showing the importance and functioning of the simulation operation. This can be done by fixing objectives and choosing the appropriate instruments.

\subsubsection{Teachings withdrawn}

As far as simulation is concerned, it is, therefore possible to combine the fiscal policies and investment along with the prices and subsidies policies. In this case, the induced effects would affect the whole system. In our case, action on subsidies and total costs remains one of the best combinations for the purpose of maximizing profits. Indeed, maximizing profits means the maximization of the gap between incomes and the total costs. Thus, all measures aiming at the reduction of costs, accompanied with an increase of incomes, would be at the origin of the improvement of profit levels. This justifies the recorded change as regards the balance, either in the case of free access or in the case of controlled access as well. Therefore, each increase in basic sale prices of fish or/and each decrease in total costs would lead to a new balance, either in the case of controlled or free access while demanding a more important effort, within the limits of the MSY in order to maximize profits. However, this may raise problems in the case of free access.

\section{Conclusion}

This study has attempted to shed light on the practical and efficient character of the PES and its ability in simulation. Such a simulation has become very important to the public policies and management of fisheries as well. In addition to pedagogical contribution, the use of PES in managing the Gulf of Ziama, will contribute to the understanding of complex fishing systems. It is, also, an interesting tool that could help to set up future policies necessary for developing the fishing sector, especially in developing countries.

The PES can be referred as a rich source of quantitative and qualitative of information. Besides its informative character (syntheses and graphics), the PES permits to display orientations relative to the bioeconomical situation of the fishery. Recommendations are, theoretically, based on an expert evaluation that draws from the theoretical foundations of the fishing economy and based on the hypotheses of the Pêchakour model. This makes the PES an expert system.

In addition to using the Pêchakour model, the PES offers the possible use of the Gordon-Schaefer model as informative and educational as well. Altogether, this test which aims to show the efficiency of PES through its utilization in the management of the gulf of Ziama proves to be suitable, appropriate and efficient at the same time.

\section{References}

[1] Boncoeur, B., Le mécanisme de la surexploitation des ressources halieutiques, Académie des Sciences rst n²17, décembre 2003, Ed. TEC \& DOC, Lavoisier, 2003. 
[2] Chakour, S.-C. \& Alegret Tegero, J., Evolucion institucional y desarrolo del sector pesquero en Argelia; Palamos : Ayntamiento de Palamos, 2006, Collectccion : Quaderns Blaus, Espagna.18.Dec.2006.

[3] Le Gallic, B., Modélisation bioéconomique et gestion durable d'un système complexe de ressources communes renouvelables. Application au cas des pêcheries de la Manche. hèse de Doctorat de l'Université de Bretagne Occidentale, Mention Sciences Economiques, mai 2001.

[4] Chakour, S.-C. \& Boncoeur, J., Un modèle bioéconomique pour une gestion durable des pêcheries en Algérie: le modèle Pêchakour. In les Cahiers du CREAD $\mathrm{N}^{\circ} 72 / 2005$.

[5] Chakour, S.-C., Economie des pêches en Algérie ; Thèse de Doctorat, INA, Alger, Algérie, 2006.

[6] Chakour, S.-C., Une approche empirique pour une gestion durable des pêcheries en Algérie. Colloque international "L'ETAT MALGRE TOUT? ACTEURS PUBLICS ET DEVELOPPEMENT", MONS (Belgique), 1416 mai 2007.

[7] Gordon, H.S., The economic theory of a common property resource, the fishery, Journal of Political Economics, vol.62, n², 1954.

[8] Schaefer, M., Some considerations of population dynamics and economics in relation to the management of marine fisheries, Journal of Fisheries Research Board of Canada, vol.14, n5, 1957.

[9] Clark, C.-W., Mathematical bioeconomics: The optimal management of renewable resources, Second edition. A Wiley-Interscience Publication, USA., 1931.

[10] Gordon, H.S., An economic approach to the optimum utilization of fisheries resources, Journal of Fisheries Research Board of Canada, vol. 10, $\mathrm{n}^{\circ}$ 7, 1953.

[11] Mesnil, B., Dynamique des populations exploitées et principaux modèles démographiques appliqués à la gestion des pêches; Rapport sur la science et la technologie, Académie des Sciences, rst $\mathrm{n}^{\circ}$ 17, Chapitre 5, décembre, 2003. , Edition TEC \& DOC, LAVOISIER, 2003. 